\title{
The shape of D-glucosamine
}

\author{
Isabel Peña, Lucie Kolesniková, Carlos Cabezas, Celina Bermúdez, Matías Berdakin, Alcides Simão and \\ José L. Alonso*
}

The bioactive amino monosaccharide $\mathrm{D}$-glucosamine has been generated in gas phase via laser ablation of D-glucosamine hydrochloride. Three cyclic $a-{ }^{4} C_{1}$ pyranose forms have been identified using Fourier transform microwave techniques. Stereoelectronic hyperconjugative forces - essentially linked with the anomeric or gauche effect - and cooperative $\mathrm{OH}^{*} \mathrm{O}, \mathrm{OH}^{\prime \prime} \mathrm{N}$ and $\mathrm{NH}^{*} \mathrm{O}$ chains, extended along the entire 10 molecule, are found to be the main factors driving the conformational behavior. The orientation of the $\mathrm{NH}_{2}$ group within each conformer has been determined by the values of the nuclear quadrupole constants. The results have been compared with those recently obtained for the archetypical D-glucose.

\section{Introduction}

The first conformational characterization of isolated D-glucose 15 molecule in gas phase became recently possible due to the latest developments of Fourier tranform microwave techniques coupled with laser ablation vaporizations methods. ${ }^{1}$ For this archetypical monosaccharide, four conformers of a-D-glucopyranose and three of $\beta$-D-glucopyranose have been unequivocally identified.

20 D-glucosamine $\left(\mathrm{C}_{6} \mathrm{H}_{13} \mathrm{NO}_{5}\right.$, see Figure 1a) is a bioactive amino monosaccharide that differs structurally from the parent $\mathrm{D}$ - glucose by replacement of the hydroxyl group on $\mathrm{C}_{2}$ by an amino group. In the human body, glucosamine is biochemically formed as glucosamine-6-phosphate, ${ }^{2}$ which is an essential precursor for

25 subsequent synthesis of important nitrogen-containing macromolecules, such as glycoproteins, glycolipids and glycosaminoglycans, known as building blocks of the joint cartilage and connective tissues, contributing to their strength and flexibility. ${ }^{3}$ Glucosamine salts, derivatives and glucosamine-

30 containing polymers have potential to be used in numerous biomedical applications. ${ }^{3-7}$

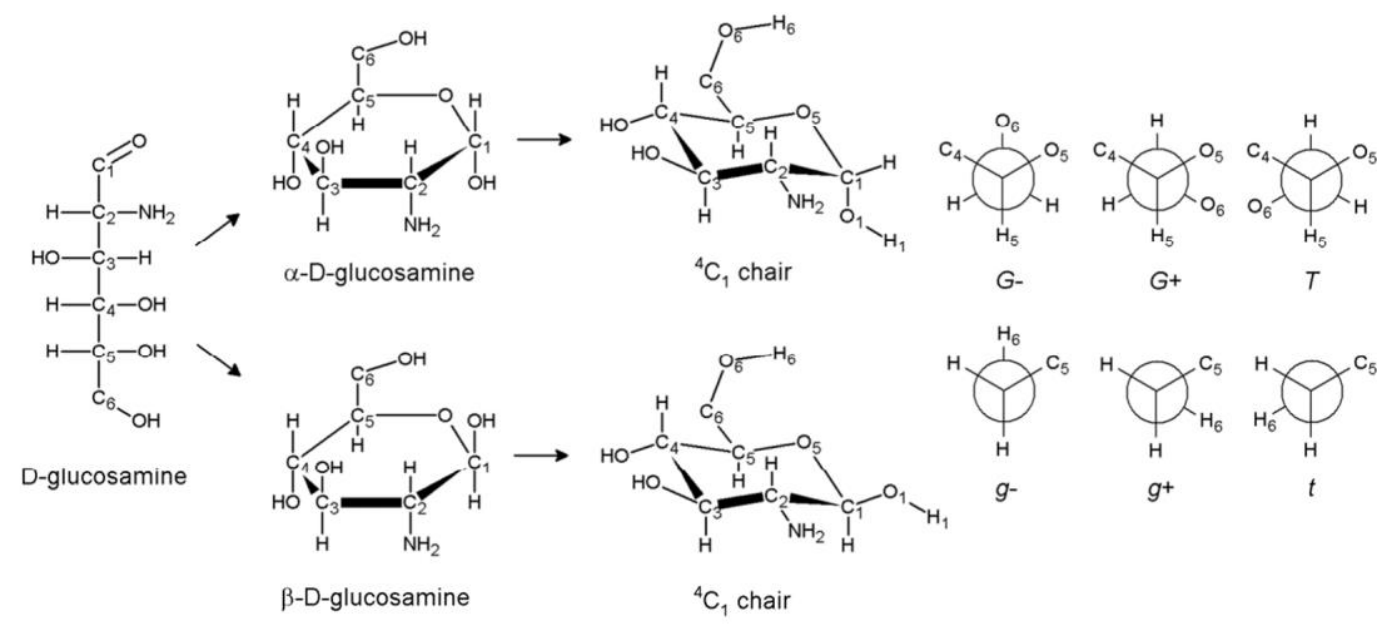

(a)

(b)

(c)

(d)

Fig. 1 (a) Fisher projection of D-glucosamine; (b) a- and $\beta$-anomers of D-glucosamine in Haworth projection; (c) ${ }^{4} \mathrm{C}_{1}$ conformations of a- and and $\beta$-Dglucosamine; (d) Newman projections of plausible conformations of the hydroxymethyl group around the $\mathrm{C}_{5}-\mathrm{C}_{6}(G-, G+, T)$ and $\mathrm{C}_{6}-\mathrm{O}_{6}(g-, g+, t)$ bonds.

35 In the pure form, D-glucosamine is chemically unstable; promptly reacting when exposed to the atmosphere, and is thus only commercially available as a salt, where it appears in the protonated form. Hence, most of the experimental studies on Dglucosamine salts have been performed in either the solid ${ }^{8-10}$ or
40 liquid phases. $^{10-15} \mathrm{X}$-ray crystallography experiments on Dglucosamine hydrochloride indicate that the protonated glucosamine exists in the a-anomeric pyranose form, in the preferred ${ }^{4} \mathrm{C}_{1}$ chair conformation. ${ }^{8,9}$ When dissolved in water, the a-pyranose form is slowly transformed into the $\beta$-form, until it 


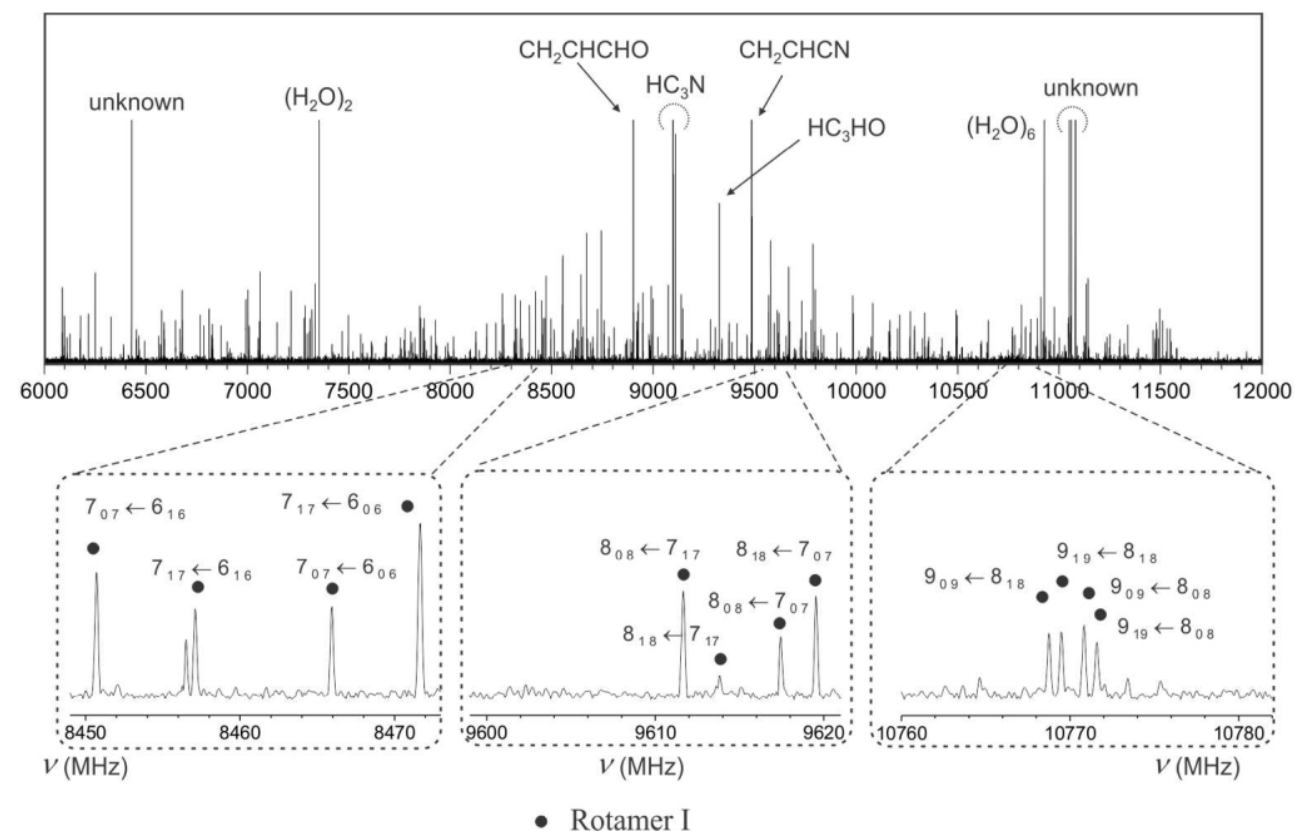

Fig. 2 Upper panel: overview CP-FTMW spectrum of the laser ablated a-D-glucosamine with assigned decomposition lines; lower panels: a-type $(\mathrm{J}+1)_{0 \mathrm{~J}+1} \leftarrow \mathrm{J}_{0 \mathrm{~J}},(\mathrm{~J}+1)_{1 \mathrm{~J}+1} \leftarrow \mathrm{J}_{1 \mathrm{~J}}$ and b-type $(\mathrm{J}+1)_{1 \mathrm{~J}+1} \leftarrow \mathrm{J}_{0 \mathrm{~J}},(\mathrm{~J}+1)_{0 \mathrm{~J}+1} \leftarrow \mathrm{J}_{1 \mathrm{~J}}$ progressions in detail corresponding to the observed rotamer $\mathrm{I}$; rotational transitions become degenerated with the increasing $\mathrm{J}$.

5 reaches the equilibrium anomeric composition of a: $\beta \sim 63: 37$ as observed from optical rotation and nuclear magnetic resonance (NMR) experiments. ${ }^{11,12}$ Interestingly, these results contrast with those obtained for D-glucose, where the reversed ratio of the two anomeric forms has been reported. ${ }^{12,14-16}$ Despite the biological

10 and medical importance of D-glucosamine, no experimental data on the conformational behavior of its neutral form has been reported hitherto.

At the University of Valladolid, efficient procedures have been developed for generation of neutral forms of proteogenic amino 15 acids in supersonic expansion by laser ablation of its zwitterionic forms, allowing their conformational investigation using Fourier transform microwave techniques. ${ }^{17,18}$ These experimental approaches have also been applied successfully to many other biologically relevant molecules, and, recently, several conformers 20 of the monosaccharides D-glucose, ${ }^{1} \mathrm{D}$-xylose,${ }^{19} \mathrm{D}$-fructose,${ }^{20} \mathrm{D}$ ribose $^{21}$ 2-deoxy-D-ribose ${ }^{22}$ and D-erythrose ${ }^{23}$ have been identified and characterized structurally. In the present study, the conformational behavior of D-glucosamine, successfully generated in the gas phase by laser ablation of its hydrochloride 25 salt, is reported for the first time.

\section{Experimental}

A commercial sample of D-glucosamine hydrochloride (m.p. = $190-194{ }^{\circ} \mathrm{C}$ ) was used without any further purification. A solid rod was prepared by pressing the compound's fine powder mixed

30 with a small amount of commercial binder and was placed into the ablation nozzle. A picosecond Nd:YAG laser $(10 \mathrm{~mJ}$ per pulse, 35 ps pulse width) was used as vaporization tool. Products of the laser ablation were supersonically expanded using the flow of carrier gas (Ne, 15 bar) into the vacuum chamber of the 35 spectrometers. D-glucosamine was first investigated using a chirped pulse Fourier transform microwave (CP-FTMW) spectrometer coupled with laser ablation to sample swiftly the rotational spectra of the different conformers present in the gasphase mixture. Details of the experimental setup have been given ${ }_{40}$ elsewhere. ${ }^{17}$ Up to 70000 individual free induction decays were averaged in the time domain and Fourier transformed to obtain the rotational spectrum from 6 to $12 \mathrm{GHz}$ shown in the upper panel of Figure 2. A Kaiser-Bessel window was applied to increase the baseline resolution. The sub-Doppler resolution of 45 the laser ablation molecular beam Fourier transform microwave (LA-MB-FTMW) technique, ${ }^{18}$ operating from 4 to $18 \mathrm{GHz}$, was used to resolve the hyperfine structure due to the ${ }^{14} \mathrm{~N}$ nucleus. A short microwave radiation pulse of $0.3 \mu$ s duration was applied to polarize all the vaporized molecules. The registered free ${ }_{50}$ induction decay was then converted to the frequency domain by Fourier transformation. All the transitions appeared as Doppler doublets due to the parallel configuration of the molecular beam and the microwave radiation. The resonance frequency was determined as the arithmetic mean of the two Doppler

55 components. Frequency accuracy better than $5 \mathrm{kHz}$ and an estimated resolution of $7 \mathrm{kHz}$ are achieved in the experiment.

\section{Results}

\section{a. Modelling}

Similarly to D-glucose and other hexoses, D-glucosamine may 60 exist in linear or cyclic forms, with the six-membered aldopyranose ring being the most stable species ${ }^{24}$ (see Figure 1b). The formation of this ring structure is the result of a cyclization process through the nucleophilic attack of the hydroxyl group located at $\mathrm{C}_{5}$ to the carbonyl carbon atom $\left(\mathrm{C}_{1}\right)$, which may lead to ${ }_{65}$ formation of $\mathrm{a}$ and $\beta$ anomeric forms. The pyranose ring might assume either of two chair ${ }^{1} \mathrm{C}_{4}$ or ${ }^{4} \mathrm{C}_{1}$ configurations (see Figure 1c), but being dominant the latter, where the hydroxymethyl $\mathrm{CH}_{2} \mathrm{OH}$ group is in equatorial position and is energetically 
Table 1. Molecular properties for the a- and $\beta$ - lowest energy conformers of D-glucosamine (below $600 \mathrm{~cm}^{-1}$ ).

\begin{tabular}{lccccccccccc}
\hline & $\mathrm{A}^{a}$ & $\mathrm{~B}$ & $\mathrm{C}$ & $\mathrm{X}_{\text {aa }}$ & $\mathrm{X}_{\mathrm{bb}}$ & $\mathrm{X}_{\mathrm{cc}}$ & $\left|\mu_{\mathrm{a}}\right|$ & $\left|\mu_{\mathrm{b}}\right|$ & $\left|\mu_{\mathrm{c}}\right|$ & $\Delta \mathrm{E}^{b}$ & $\Delta \mathrm{G}^{c}$ \\
\hline a-G-g+/cc/t & 1276 & 784 & 581 & 2.21 & -3.92 & 1.70 & 3.0 & 3.8 & 0.1 & 0 \\
a-G+g-/cc/t & 1313 & 763 & 534 & 0.66 & -2.44 & 1.78 & 3.0 & 3.2 & 1.2 & 31 \\
a-Tg+/cc/t & 1398 & 740 & 538 & 2.54 & -4.33 & 1.79 & 4.1 & 1.7 & 0.9 & 113 \\
a-G-g+/cl/g- & 1296 & 788 & 573 & 2.76 & 0.51 & -3.26 & 1.0 & 0.7 & 1.2 & 329 \\
a-Tt/cl/g- & 1404 & 752 & 544 & 2.76 & 0.46 & -3.22 & 2.4 & 0.6 & 0.3 & 541 \\
a-Tg-/cl/g- & 1400 & 748 & 542 & 2.75 & 0.40 & -3.15 & 0.1 & 0.5 & 0.0 & 587 \\
& & & & & & & & & & \\
$\beta-G-g+/ c c / t$ & 1177 & 818 & 535 & 2.34 & -3.37 & 1.03 & 2.8 & 2.2 & 2.5 & $0^{d}$ & 0 \\
$\beta-G+g-/ c c / t$ & 1180 & 790 & 495 & 0.70 & -2.38 & 1.68 & 2.6 & 2.0 & 1.0 & 37 \\
$\beta-T g+/ c c / t$ & 1317 & 735 & 495 & 2.40 & -4.10 & 1.71 & 3.2 & 0.4 & 1.0 & 140 \\
\hline
\end{tabular}

${ }^{a} \mathrm{~A}, \mathrm{~B}$, and $\mathrm{C}$ represent the rotational constants (in $\mathrm{MHz}$ ); $\mathrm{X}_{\mathrm{aa}}, \mathrm{X}_{\mathrm{bb}}$ and $\mathrm{X}_{\mathrm{cc}}$ are the diagonal elements of the ${ }^{14} \mathrm{~N}$ nuclear quadrupole coupling tensor (in $\mathrm{MHz}) ; \mu_{\mathrm{a}}, \mu_{\mathrm{b}}$ and $\mu_{\mathrm{c}}$ are the electric dipole moment components (in D). ${ }^{b}$ Relative energies (in $\mathrm{cm}^{-1}$ ) with respect to the global minimum calculated at the MP2/6-311++G(d,p) level. ${ }^{c}$ Gibbs energies calculated at $298 \mathrm{~K} .{ }^{d}$ The $\mathrm{a}$-anomer species is predicted to be $579 \mathrm{~cm}^{-1}$ more stable than the $\beta$-anomer.

favored $^{1}$ (see Figure 1c). On this basis, ab initio calculations were performed on a- and $\beta-{ }^{4} C_{1}$ configurations to obtain the lowerenergy conformations and their relative Gibbs energies. Six $a$ and three $\beta$ forms have been predicted below $600 \mathrm{~cm}^{-1}$ (see Table 1).

${ }_{5}$ The $\mathrm{a}$ and $\beta$ glucosamine's conformers have been labeled according to the hydroxymethyl group configurations. ${ }^{1,25}$ Three staggered forms, designated $G^{-}, G+$ (gauche) and $T$ (trans) (see Figure 1d), and represented by the $\mathrm{O}_{6}-\mathrm{C}_{6}-\mathrm{C}_{5}-\mathrm{O}_{5}$ dihedral angle with the values of approximately $-60^{\circ}, 60^{\circ}$ and $180^{\circ}$,

10 respectively, have been considered. In the same way, the symbols $g-, g+$ and $t$ describe the conformations defined by the $\mathrm{H}_{6}-\mathrm{O}_{6}-\mathrm{C}_{6}-\mathrm{C}_{5}$ dihedral angle. The symbols $c c$ or $c l$ after the first slash denote, respectively, the counterclockwise or clockwise arrangement of the cooperative network of intramolecular 15 hydrogen bonds. Finally, after the second slash, the symbols $g-$, $g+$ and $t$ represent the orientation of the anomeric hydroxyl group hydrogen atom defined by the $\mathrm{H}_{1}-\mathrm{O}_{1}-\mathrm{C}_{1}-\mathrm{C}_{2}$ dihedral angle.

6-311 Moller-Plesset sezond order method (MP2) and the

20 the structures and to calculate the relevant spectroscopic properties. The values of the rotational constants $(A, B, C)$, electric dipole moment components $\left(\mu_{a}, \mu_{b}, \mu_{c}\right)$ and the electric quadrupole coupling constants $\left(\mathrm{X}_{a a}, \mathrm{X}_{b b}, \mathrm{X}_{c c}\right)$ for these conformers are reported in Table 1.

\section{5 b. Broadband CP-FTMW rotational spectrum analysis}

The recorded broadband rotational spectrum of laser ablated of D-glucosamine hydrochloride from 6 to $12 \mathrm{GHz}$ is shown in Figure 2. Soon, decomposition products lines common to other studies of sugars $^{20 a}$ and amino acids ${ }^{27}$ (see Figure 2, upper panel) 30 attributable to cyanoderivatives, formadelhyde, etc. were easily identified. After excluding the aforementioned signals from the spectral analysis, the identification of rotational transitions belonging to a first species, labeled as rotamer $\mathrm{I}$, was accomplished. Assignments were based on the identification in 35 the broadband spectrum of $a$-type $(J+1)_{0 J+1} \leftarrow J_{0 J},(J+1)_{1 J+1}$ $\leftarrow J_{1 J}$ and $b$-type $(J+1)_{1 J+1} \leftarrow J_{0 J},(J+1)_{0 J+1} \leftarrow J_{1 J}$ pairs of rotational progressions, which became degenerated with increasing $\mathrm{J}$ (Figure 2, lower panels). Following an iterative procedure of fitting and subsequent predictions, more $a$-type and ${ }_{40} b$-type transitions were assigned in the range from $J=3$ to $J=8$.
On the same basis, further searches in the broadband spectrum made possible the assignment of rotational transitions of another two rotamers: II and III. For rotamer III, only a-type rotational transitions were observed. No other rotamers were found in the 45 broadband rotational spectrum.

Table 2. Experimental spectroscopic parameters for the three observed rotamers of D-glucosamine obtained from CP-FTMW spectra.

\begin{tabular}{|c|c|c|c|}
\hline Parameter & Rotamer I & Rotamer II & Rotamer III \\
\hline $\mathrm{A}^{a} / \mathrm{MHz}$ & $1269.4108(23)^{e}$ & $1305.3545(29)$ & $1389.896(18)$ \\
\hline $\mathrm{B} / \mathrm{MHz}$ & 781.1783 (13) & 760.1481 (12) & $738.65091(94)$ \\
\hline $\mathrm{C} / \mathrm{MHz}$ & $577.43929(36)$ & $531.25706(33)$ & $535.50479(54)$ \\
\hline a-type ${ }^{b}$ & observed & observed & observed \\
\hline b-type & observed & observed & - \\
\hline c-type & - & - & - \\
\hline $\mathrm{N}^{c}$ & 31 & 42 & 21 \\
\hline$\sigma_{a}{ }^{d i t} / \mathrm{kHz}$ & 23.3 & 26.1 & 19.2 \\
\hline
\end{tabular}

and c-type transitions for each structure. ${ }^{c}$ Number of fitted transitions. ${ }^{d}$ RMS deviation of the fit. ${ }^{e}$ Standard error in parenthesis in the units of the last digit.
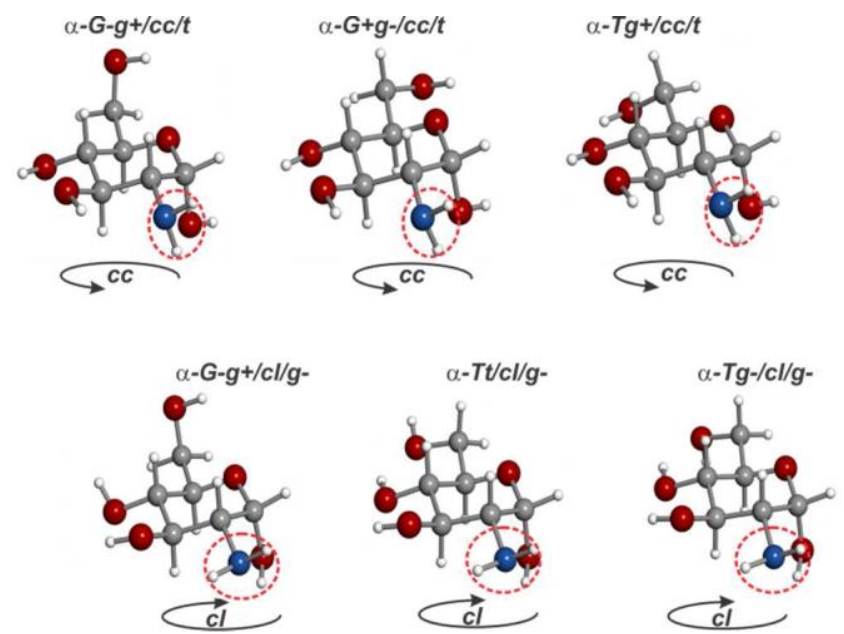

Fig. 3 The most stable conformers of a-D-glucosamine (below $600 \mathrm{~cm}^{-1}$ ), showing the $c c$ configuration in conformers $G-g+/ c c / t, G+g-/ c c / t$ and $\mathrm{Tg}+/ \mathrm{ccl} t \mathrm{t}$ and the $\mathrm{cl}$ one in conformers $\mathrm{G}-\mathrm{g}+/ \mathrm{cl} / \mathrm{g}_{-}, \mathrm{Tt} / \mathrm{cl} / \mathrm{g}_{\text {- }}$ and $\mathrm{Tg}-/ \mathrm{cl} / \mathrm{g}_{-}$. 
Some observed transitions show partial resolved hyperfine structure as corresponding to a compound with one ${ }^{14} \mathrm{~N}$ nucleus. No transition with a quadrupole hyperfine structure as corresponding to a chlorine nucleus was found. These 5 experimental facts confirmed the generation of neutral glucosamine in the gas phase by laser ablation of crystalline Dglucosamine hydrochloride and the absence of the salt in the supersonic expansion. Thus, the three observed rotamers can be ascribed to different glucosamine conformers. Since the spectral 10 resolution attainable in the CP-FTMW experiments is not sufficient to completely resolve these hyperfine effects, only transitions with unresolved hyperfine structure (see Tables S1-S3 of the ESI $\dagger$ ) were $\mathrm{fit}^{28}$ to a rigid rotor Hamiltonian to derive a first set of the rotational constants listed in Table 2. The 15 comparison of these experimental values with those predicted in

Table 1 for the $a$ and $\beta$ forms of glucosamine clearly indicates that the three observed rotamers belong to $a$ forms of

glucosamine shown in Figure 3. The values of the rotational constants reflect directly the mass distribution of the conformers,

20 which is substantially different in $a$ and $\beta$ forms. Dealing with $a$ forms, it could be hypothesized that rotamer I could be the $G$ $g+/ c c / t$ or $G-g+/ c l / g$ - conformers and rotamer III the $T g+/ c c / t$, $\mathrm{Tt} / \mathrm{cl} / \mathrm{g}_{-}$, or $\mathrm{Tg}-\mathrm{cl} / \mathrm{g}$ - conformers, while rotamer II can be definitively assigned to $\mathrm{G}+\mathrm{g}-\mathrm{/cc} / \mathrm{t}$ conformer. If two conformers 25 present similar mass distribution, the rotational constants cannot be used to unambiguously distinguish between them. Hence, other conformational tools are needed for a conclusive identification.

The intramolecular hydrogen bond network arrangements, 30 counterclockwise $(c c)$ or clockwise $(c l)$ (see Figure 3), significantly changes the predicted values of the dipole moment components for the six plausible low-energy conformes of the a forms (see Table 1). It, consequently, affects the observable type of transitions. Table 2 documents that none of $c$-type transition 35 was observed for the various rotamers. If rotamer I was indeed the $G$ - $g+/ c l / g$ - conformer, $c$-type transitions should be observable, since $\mu_{a} \approx \mu_{c}$. Thus, rotamer I could be tentatively assigned to $G$ - $g+/ c c / t$ conformer. For rotamer III, only $a$-type transitions were observed, so conformer $\mathrm{Tg}-\mathrm{cl} / \mathrm{g}$ - should be ${ }_{40}$ excluded due to very low predicted value for this dipole moment component. It is still not possible to distinguish between conformers $T g+/ c c / t$ and $T t / c l / g$-.

A more straightforward way to distinguish unambiguously between conformers is to take into account the values of nuclear ${ }_{45}$ quadrupole hyperfine constants that can be extracted from the hyperfine structure of rotational transitions. The nuclear quadrupole coupling constants derived from the analysis are very sensitive to the orientation of the $-\mathrm{NH}_{2}$ group with respect to the principal axes system. As shown in Table 1, the predicted values ${ }_{50}$ for the diagonal elements of the quadrupole coupling tensor $X_{a a}$, $\mathrm{X}_{b b}, \mathrm{X}_{c c}$ change dramatically going from the $c c$ configuration in conformers $G-g+/ c c / t$ and $T g+/ c c / t$ to the $c l$ ones in conformers $\mathrm{G}-\mathrm{g}+/ \mathrm{cl} / \mathrm{g}$ - and $\mathrm{Tg}-/ \mathrm{cl} / \mathrm{g}$ - (see Figure 3 ), since the $-\mathrm{NH}_{2}$ group shows opposite orientation in both $c c$ and $c l$ arrangements to ${ }_{55}$ participate in the intramolecular hydrogen bond networks. A high resolution rotational study by LA-MB-FTMW spectroscopy is needed to completely resolve the ${ }^{14} \mathrm{~N}$ nuclear quadrupole
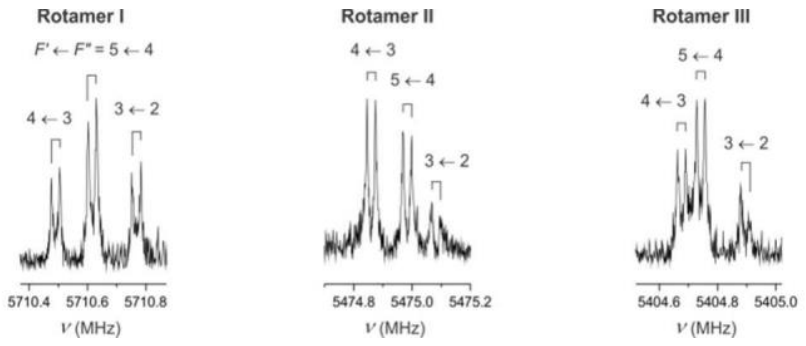

Fig. 4 Nuclear quadrupole hyperfine structure of the $4_{13} \leftarrow 3_{12}$ rotational 60 transition for rotamers I, II and III. Each component labeled as $\mathrm{F}^{\prime} \leftarrow \mathrm{F}^{\prime \prime}$ is observed as a doublet due to the Doppler effect. The molecular frequency is the arithmetic mean of the Doppler doublets.

Table 3. Experimental spectroscopic parameters for the three observed rotamers of D-glucosamine obtained from LA-MB-FTMW spectra.

\begin{tabular}{|c|c|c|c|}
\hline Parameter & $\begin{array}{c}\text { Rotamer I } \\
\left(a-G_{-}-g+/ c c / t\right)\end{array}$ & $\begin{array}{c}\text { Rotamer II } \\
\text { (a- } G+g-/ c c / t)\end{array}$ & $\begin{array}{l}\text { Rotamer III } \\
(\mathrm{a}-T g+/ c c / t)\end{array}$ \\
\hline $\mathrm{A}^{a} / \mathrm{MHz}$ & $1269.4100(15)^{e}$ & $1305.34810(82)$ & $1390.0011(14)$ \\
\hline $\mathrm{B} / \mathrm{MHz}$ & $781.18234(26)$ & 760.14999 (14) & $738.65282(13)$ \\
\hline $\mathrm{C} / \mathrm{MHz}$ & $577.437380(86)$ & $531.255624(50)$ & $535.499914(56)$ \\
\hline $\mathrm{X}_{\text {aа }}{ }^{b} / \mathrm{MHz}$ & $2.159(16)$ & $0.637(5)$ & 2.487 (6) \\
\hline $\mathrm{X}_{\mathrm{bb}} / \mathrm{MHz}$ & $-3.727(14)$ & $-2.278(4)$ & $-4.129(5)$ \\
\hline $\mathrm{X}_{\mathrm{cc}} / \mathrm{MHz}$ & 1.567 (14) & $1.641(4)$ & $1.642(5)$ \\
\hline & 32 & 30 & 18 \\
\hline$\sigma_{\mathrm{fit}}{ }^{d} / \mathrm{kHz}$ & 1.3 & 1.3 & 1.1 \\
\hline
\end{tabular}

${ }^{a} \mathrm{~A}, \mathrm{~B}$, and $\mathrm{C}$ represent the rotational constants. ${ }^{\mathrm{Xa}}, \mathrm{X}_{\mathrm{bb}}$ and $\mathrm{X}_{\mathrm{cc}}$ are the diagonal elements of the ${ }^{14} \mathrm{~N}$ nuclear quadrupole coupling tensor. ${ }^{c}$ Number of fitted transitions. ${ }^{d}$ RMS deviation of the fit. ${ }^{e}$ Standard error in parenthesis in the units of the last digit

hyperfine structure, and to achieve a conclusive identification of the observed rotamers.

\section{${ }_{65}$ c. High resolution LA-MB-FTMW spectra}

A new series of experiments on laser ablated D-glucosamine hydrochloride were carried out using our LA-MB-FTMW technique. The nuclear quadrupole coupling hyperfine structure for the rotational transitions of the observed rotamers was fully 70 resolved as shown in Figure 4 for the $4_{13}-3_{12}$ transition. A total of 32, 30 and 18 quadrupole hyperfine components were measured for rotamers I, II and III, respectively (Tables S4-S6 of the ESI $\dagger$ ). They were analyzed using the effective Hamiltonian $H=H_{\text {ROT }}+$ $H_{\mathrm{Q}}$, where $H_{\text {ROT }}$ represents the rigid rotor Hamiltonian and $H_{\mathrm{Q}}$ the 75 quadrupole coupling Hamiltonian. ${ }^{29}$ Using the $F=J+I$ angular momentum coupling scheme, the energy levels involved in each transition were thus labeled with the quantum numbers $J, K_{-l}$, $K_{+l}$, and $F$. Experimentally derived rotational constants $A, B, C$ together with the diagonal elements of the quadrupole coupling

${ }_{80}$ tensor $X_{a a}, X_{b b}, X_{c c}$ for each rotamer are given in Table 3. Contributions of the off-diagonal elements of the nuclear quadrupole coupling tensor to the observed frequencies were found to be negligible, and therefore these parameters were not determined.

85 At first, a comparison of the experimentally obtained values of the electric quadrupole coupling constants for rotamer II (see Table 3) with the predicted ones (see Table 1) was made to confirm its assignment to the $G+g-/ c c / t$ conformer. The excellent agreement among both sets of data confirms the assignment

90 based on the rotational constants. Similarly, the experimental electric quadrupole coupling constants for rotamers I and III were 


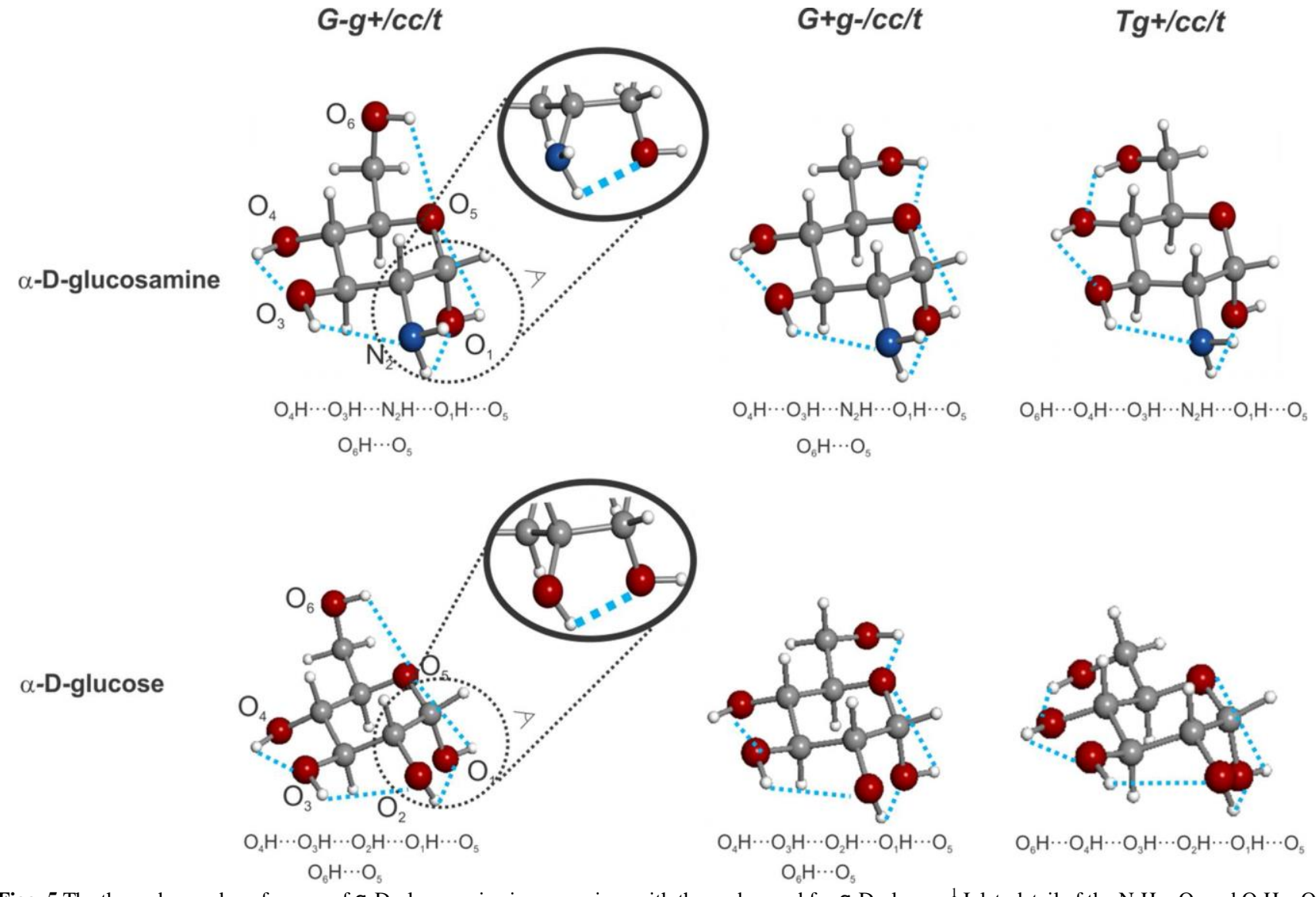

Figg. 5 The three observed conformers of a-D-glucosamine in comparison with those observed for a-D-glucose. ${ }^{1}$ Inlet: detail of the $\mathrm{N}_{2} \mathrm{H}^{\cdots} \mathrm{O}_{1}$ and $\mathrm{O}_{2} \mathrm{H} \cdots \mathrm{O}_{1}$ hydrogen bonds for $\mathrm{G}-\mathrm{g}+/ \mathrm{cc} / \mathrm{t}$ conformers of a-D-glucosamine and $\mathrm{a}$-D-glucose, respectively. The amino group $\mathrm{NH}_{2}$ in $\mathrm{a}$-D-glucosamine assumes the same role in the intramolecular hydrogen bonding than the hydroxyl group $\mathrm{OH}$ in a-D-glucose.

compared with those predicted for the related conformers' candidates (see Tables 3 and 1), unambiguously showing that rotamer I corresponds to the $G$ - $g+/ c c / t$ conformer and rotamer III corresponds to the $T g+/ c c / t$ conformer.

\section{${ }_{10}$ Discussion}

The observation of only a-forms deserves some explanation. It should be noted that, as observed in previous studies, ${ }^{30,31}$ the laser ablation of solid samples of the crystalline D-glucosamine hydrochloride generates into the gas phase neutral D-glucosamine

15 in its a-pyranose form, thus preserving the a-pyranose species present in the X-ray studies. ${ }^{1,19}$ The interconversion between the $a$ and $\beta$ anomers is a solvent-mediated reaction and thus should not occur that easily during evaporation, ${ }^{32}$ especially if the sample is completely dry. ${ }^{33} \mathrm{In}$ any case, the most stable $\beta$ form, $\beta-\mathrm{G}-$ ${ }_{20} \mathrm{~g}+/ c c / \mathrm{t}$, is predicted $579 \mathrm{~cm}^{-1}$ above the most stable $\mathrm{a}-\mathrm{G}-\mathrm{g}+/ \mathrm{cc} / \mathrm{t}$ one.

The three observed a-pyranose forms of D-glucosamine, G$\mathrm{g}+/ c c / \mathrm{t}, \mathrm{G}+\mathrm{g}-/ c c / \mathrm{t}$ and $\mathrm{Tg}+/ c c / \mathrm{t}$, are stabilized by the endo anomeric effect; they present a ${ }^{4} \mathrm{C}_{1}$ ring configuration, thus ${ }_{25}$ leading the anomeric $\mathrm{OH}$ group towards the axial position. ${ }^{34}$ The hydroxyl groups are located at the same side of the ring to form a hydrogen bond network, which in turn, is reinforced by sigma hydrogen-bond cooperativity. ${ }^{35}$ In this way, the two most stable conformers $\mathrm{G}+\mathrm{g}-/ c c / \mathrm{t}$ and $\mathrm{G}-\mathrm{g}+/ c c / \mathrm{t}$ are stabilized by a chain of 30 four cooperative hydrogen bonds $\left(\mathrm{O}_{4} \mathrm{H} \cdots \mathrm{O}_{3} \mathrm{H} \cdots \mathrm{N}_{2} \mathrm{H} \cdots \mathrm{O}_{1} \mathrm{H} \cdots \mathrm{O}_{5}\right)$ and one non-cooperative $\mathrm{O}_{6} \mathrm{H} \cdots \mathrm{O}_{5}$ bond, as depicted in Figure 5. The least stable conformer $T g+/ c c / t$ exhibits five cooperative hydrogen bonds $\left(\mathrm{O}_{6} \mathrm{H} \cdots \mathrm{O}_{4} \mathrm{H}^{\cdots} \mathrm{O}_{3} \mathrm{H} \cdots \mathrm{N}_{2} \mathrm{H} \cdots \mathrm{O}_{1} \mathrm{H} \cdots \mathrm{O}_{5}\right)$, including the stronger $\mathrm{H}$-bond between $\mathrm{O}_{6} \mathrm{H}$ and $\mathrm{O}_{4} \mathrm{H}$ which is, for sugars 35 with $\mathrm{O}_{4} \mathrm{H}$ equatorial group, favorable only in the trans configuration. Relative abundances of the three conformers have been estimated from the relative intensities of the rotational transitions, and found to be G-g+/cc/t : G+g$/ c c / t: \mathrm{Tg}+/ c c / \mathrm{t} \approx 0.7(1): 1: 0.2(1)$, in qualitatively agreement 40 with those predicted for Gibbs energies in Table 1.

The observation of a trans configuration for a-D-glucosamine, $\mathrm{Tg}+\mathrm{ccc} / \mathrm{t}$, represents a remarkable fact, since numerous experimental studies on glucopyranosides in condensed phases, ${ }^{36-}$

${ }^{38}$ have shown that the dihedral angle (O6-C6-C5-O5) displays a ${ }_{45}$ preference towards G- and $\mathrm{G}+$ gauche configuration, with an almost complete absence of the trans (T). Our results are in agreement with $a b$ initio computations, which predict the trans conformer enough populated to be detected in the supersonic expansion. In any case, the hydroxymethyl group's gauche (G) 50 configurations of D-glucosamine also dominate in the gas phase, which can in principle be seen as a consequence of contributions of factors like the so-called gauche effect, ${ }^{39}$ associated with the stabilization of the synclinal (gauche) conformation of two 
vicinal electronegative groups bonded to a two carbon unit. The same conformational behavior has been observed in the archetypical a-D-glucopyranose.

As shown in Figure 5, the three observed conformers of a-D5 glucosamine and the three lower-energy conformers of a-Dglucose $^{1}$ exhibit the same configuration of the exocyclic hydroxymethyl group, as well as the same orientation of the intramolecular hydrogen bond network $(c c)$. Their relative abundances are also comparable with those previously reported 10 for the corresponding conformers of a-D-glucose. ${ }^{1}$ The fourth conformer in order of increasing energy $(G-g+/ c l / g-)$ of a-Dglucosamine has not been detected, in contrast to that observed for a-D-glucose. This fact can be easily explained by its higher relative energy and, consequently, to its small abundance in the 15 supersonic expansion.

The high resolution reached by LA-MB-FTMW experiments allows the determination of the nuclear quadrupole coupling constants, $\mathrm{X}_{a a}, \mathrm{X}_{b b}, \mathrm{X}_{c c}$. They inform on the orientation of the $\mathrm{NH}_{2}$ group with respect to the molecular frame, and allow establishing 20 the intramolecular interactions in which this functional group is involved. The inlet of Figure 5 shows how the amino group inserts into the hydrogen bond network; it adopts such as orientation to assume the same role of the $\mathrm{OH}$ - group at the $\mathrm{C}_{2}$ carbon in a-D-glucopyranose. Therefore, the amino group does 25 not introduce any changes into the gas phase conformational shape of a-D-glucosamine respect to that observed for a-Dglucose.

\section{Conclusions}

The present study provides the first experimental investigation of 30 the gas phase structures of D-glucosamine, which has led to the determination of the conformational behavior of this important amino monosaccharide. Three different conformers have been conclusively identified through their rotational spectra. As with a-D-glucopyranose, the observed conformers are stabilized by a 35 mesh of stereoelectronic hyperconjugative forces - essentially linked with the anomeric or gauche effect - and cooperative

$\mathrm{OH}^{*} \mathrm{O}$ chains extended along the entire molecule. The three observed conformers of a-D-glucosamine and the three most abundant conformers of a-D-glucose have the same 40 configurations of the hydroxymethyl group as well as the same counterclockwise arrangement of the $\mathrm{OH}$ groups. The orientation of the $\mathrm{NH}_{2}$ group within each conformer has been delineated by the values of the nuclear quadrupole constants. The $\mathrm{NH}_{2}$ group adopts the same role than the $\mathrm{OH}$ group in the intramolecular

45 hydrogen bonding network, which leads to the conclusion that the substitution of the hydroxyl group on $\mathrm{C}-2$ by the amino group does not affect the gas phase conformational behavior found in the archetypal D-glucose.

\section{Acknowledgements}

${ }_{50}$ This work has been supported by the Ministerio de Ciencia e Innovación (Grants CTQ2010-19008 and Consolider-Ingenio 2010 CSD2009-00038) and Junta de Castilla y León (Grant VA175U13).

\section{Notes and references}

55 Grupo de Espectroscopía Molecular (GEM), Unidad Asociada CSIC, Edificio Quifima, Laboratorios de Espectroscopia y Bioespectroscopia, Parque Científico UVa, Universidad de Valladolid, 47011 Valladolid, Spain. E-mail: jlalonso@qf.uva.es; Fax: +34 983186349; Tel: +34 9831866348

60

651 J. L. Alonso, M. A. Lozoya, I. Peña, J. C.López, C. Cabezas, S. Mata, S. Blanco, Chem. Sci., 2014, 5, 515.

2 S. Ghosh, H. J. Blumenthal, E. Davidson, S. Roseman, J. Biol. Chem., 1960, 235, 1265.

3 G. S. Kelly, Altern. Med. Rev., 1998, 3, 27.

704 Y. Henrotin, A. Mobasheri, M. Marty, Arthritis Research \& Therapy, 2012, 14, 201.

5 T. H. Fischer, A. P. Bode, M. Demcheva, J. N. Vournakis, J. Biomed. Mater. Res. A, 2007, 80A, 167.

6 H. Nakamura, K. Masuko, K. Yudoh, T. Kato, T Kamada, T. 75 Kawahara, International Journal of Rheumatology, 2007, 27, 213.

7 S. X. Wang, S. Laverty, M. Dumitriu, A. Plaas, M. D. Grynpas, Arthritis \& Rheumatism, 2007, 56, 1537.

8 Shirley S. C. Chu, G. A. Jeffrey, Proc. R. Soc. Lond. A., 1965, 285, 470.

809 W. T. A. Harrison, H. S. Yathirajan, B. Narayana, T. V. Sreevidya, B. K. Sarojini, Acta Cryst., 2007, E63, o3248.

10 S. C. Sahoo, A. Tharalekshmy, S. W. Ng, P. Naumov, Crystal Growth \& Design, 2012, 12, 5148

11 S. Bunel, C. Ibarra, E. Moraga, A. Blaskó, C. A. Bunton, Carbohyd. 85 Res., 1993, 244, 1.

12 D. Horton, J. S. Jewell, K. D. Philips, J. Org. Chem., 1966, 31, 4022

13 J. C. Irvine, J. C. Earl, J. Chem. Soc.Trans., 1922, 121, 2370.

14 A. Neuberger, A. P. Fletcher, Carbohyd. Res., 1971, 17, 79.

15 A. Neuberger, A. P. Fletcher, J. Chem. Soc. B: Phys. Org., 1969, 178.

9016 T. Taga, K. Osaki, Bull. Chem. Soc. Jpn., 1975, 48, 3250.

17 S. Mata, I. Peña, C. Cabezas, J. C. López, J. L. Alonso, J. Mol. Spectrosc., 2012, 280, 91

18 I. Peña, M. E. Sanz, J. C. López, J. L. Alonso, J. Am. Chem. Soc., 2012, 134, 2305-2312.

9519 I. Peña, S. Mata, A. Martin, C. Cabezas, A. M. Daly, J. L. Alonso, Phys. Chem. Chem. Phys., 2013, 15, 18243.

20 (a) C. Bermúdez, I. Peña, C. Cabezas, A. M. Daly, J. L. Alonso, ChemPhysChem, 2013, 14, 893; (b) E. J. Cocinero, A. Lesarri, P. Écija, A. Cimas, B. J. Davis, F. J. Basterretxea, J. A. Fernández, F.

100 Castaño, J. Am. Chem. Soc. 2013, 135, 2845

21 E. J. Cocinero, A. Lesarri, P. Écija, F. J. Basterretxea, J.-U. Grabow, J. A. Fernández, F. Castaño, Angew. Chem. Int. Ed. 2012, 51, 3119.

22 I. Peña, E. J. Cocinero, C. Cabezas, A. Lesarri, S. Mata, P. Écija, A. M. Daly, Á. Cimas, C. Bermúdez, F. J. Basterretxea, S. Blanco, J. A. 105 Fernández, J. C. López, F. Castaño, J. L. Alonso, Angew. Chem. Int Ed., 2013, 52, 11840

23 C. Cabezas, I. Peña, A. M. Daly, J. L. Alonso, Chem. Commun., 2013, 49, 10826.

24 A. L. Lehninger, Principles of Biochemistry; 4th ed.; W.H. Freeman, 2004.

25 M. Hoffmann, J. Rychlewski, J. Am. Chem. Soc., 2001, 123, 2308.

26 M. J. Frisch, G. W. Trucks, H. B. Schlegel, G. E. Scuseria, M. A. Robb, J. R. Cheeseman, G. Scalmani, V. Barone, B. Mennucci, G. A. Petersson, H. Nakatsuji, M. Caricato, X. Li, H. P. Hratchian, A. F. Izmaylov, J. Bloino, G. Zheng, J. L. Sonnenberg, M. Hada, M. Ehara, K. Toyota, R. Fukuda, J. Hasegawa, M. Ishida, T. Nakajima, Y. Honda, O. Kitao, H. Nakai, T. Vreven, J. A. Montgomery Jr., J. E. Peralta, F. Ogliaro, M. Bearpark, J. J. Heyd, E. Brothers, K. N. Kudin, V. N. Staroverov, R. Kobayashi, J. Normand, K. 120 Raghavachari, A. Rendell, J. C. Burant, S. S. Iyengar, J. Tomasi, M. Cossi, N. Rega, J. M. Millam, M. Klene, J. E. Knox, J. B. Cross, V. Bakken, C. Adamo, J. Jaramillo, R. Gomperts, R. E. Stratmann, O. Yazyev, A. J. Austin, R. Cammi, C. Pomelli, J. W. Ochterski, R. L. Martin, K. Morokuma, V. G. Zakrzewski, G. A. Voth, P. Salvador, J. 125 J. Dannenberg, S. Dapprich, A. D. Daniels, O”. Farkas, J. B. 


\section{Page 7 of 7}

Foresman, J. V. Ortiz, J. Cioslowski and D. J. Fox, Gaussian 09, Revision B.01, Gaussian, Inc., Wallingford, CT, 2009.

27 M. E. Sanz, C. Cabezas, S. Mata, J. L. Alonso, J. Chem. Phys., 2014, 140, 204308.

528 H. M. Pickett, J. Mol. Spectrosc., 1991, 148, 371-377.

29 W. Gordy and R. L. Cook, Microwave Molecular Spectra, John Wiley \& Sons, New York, 3rd edn, 1984.

30 C. Cabezas, I. Peña, J. C. López, J. L. Alonso, J. Phys. Chem. Lett., 2013, 4, 486.

1031 C. Cabezas, M. Varela, I. Peña, J. C. López, J. L. Alonso, Phys. Chem. Chem. Phys., 2012, 14, 13618.

32 P. Finch, Carbohydrates: Structures, Syntheses and Dynamics, Kluwer Academic Publishers, Netherlands, 1999.

33 L. P. Guler, Y.-Q. Yu, H. I. Kenttämaa, J. Phys. Chem. A, 2002, 106, $15 \quad 6754-6764$.

34 E. Juaristi and G. Cuevas, Tetrahedron, 1992, 48, 5019-5087.

35 G. A. Jeffrey, W. Saenger, Hydrogen Bonding in Biological Structures, Springer, New York, 1991.

36 R. H. Marchessault, S. Pérez, Biopolymers, 1979, 18, 2369.

2037 K. Bock, J. Ø. Duus, J. Carbohydr. Chem., 1994, 13, 513.

38 Y. Nishida, H. Hori, H. Ohrui, H. Meguro, J. Carbohydr. Chem., $1988,7,239$

39 S. Wolfe, Acc. Chem. Res., 1972, 5, 102. 